\title{
Magazines' Representation of Women and Its Influence on Identity Construction: A South African Perspective
}

\author{
Nereshnee Govender \\ Department of Public Relations, Durban University of Technology, South Africa \\ Email: NereshneeG@dut.ac.za \\ Veena P. Rawjee \\ Department of Public Relations, Durban University of Technology, South Africa \\ Email: rawjeeve@dut.ac.za \\ Jeevarathnam P. Govender \\ Department of Marketing, Durban University of Technology \\ Email: govendej@dut.ac.za
}

Doi:10.5901/mjss.2014.v5n20p2278

\begin{abstract}
South Africa is now in its third decade of democracy and is characterised by a social and political dispensation based on the principles of freedom of expression, non-racialism and non-sexism. These values ought to be entrenched in all aspects of our society and likewise, in the media we consume. Media is a powerful tool and through its representation contributes significantly to the definition of the world around us, and thereby also to the definition of ourselves. One such area that the media influence is the way women are represented. The media takes on an interpretative role and teaches us how to 'make sense' of the world and therefore consistently privilege some issues and identities while devaluing others. The media landscape in South Africa is large, complex, robust and mature and arguably, ranks among the largest in Africa. Magazines in particular, are modern and are popular cultural forms of representation. They are one of the most influential forces in South African culture today. The aim of this paper is to explore the representation of women in magazines and the extent of how this representation influences gender identity in either empowering or limiting the development of women in society. It employs a qualitative research methodology to examine content of selected articles in South Africa's two leading weekly magazines namely DRUM and YOU. Content analysis was used to analyse specific categories of text collected from these magazines. Overall findings reveal that stereotypical, dismissive and confining representations of women prevail in magazine media content. Creating and sustaining change must involve challenging this media content to not only increase the type of coverage of women but to extend the range of diversity to include coverage a range of stories about women including achievements and success stories of women.
\end{abstract}

Keywords: Women, Media, Identity construction, representation

\section{Introduction}

The marketing of popular media has a significant impact on many aspects of our lives. Sanders (2009:1) affirms that consumer magazines for example are entwined with entertainment, fashion and music, making it almost impossible for consumers to differentiate reality from fantasy when consuming these popular media forms. Celebrities, good or bad, have been made "role-models" and are presented as people that should be emulated. Sanders (2009:1) further suggest that digital editing has created a false world that is practically impossible to achieve. Air brushing of photographs ensures that almost all the faces are strikingly pretty and the bodies, well-toned. Women are taught that seductive poses, pouts, and stances are acceptable, essential and necessary ways to be successful. Naigle (2005:7) argues that the media is an ever-pervasive influence, which helps to present, enforce, and maintain the perception that ultra-thin, non-average body forms should be the desired goal of all women. The portrayal of unblemished, over-glamorised models sends the message that in order for a woman to be successful and accepted, she must be attractive and skinny. Further to this, Pierce (1990:372) found that images in magazines portray females as being "neurotic, helpless, and timid beings that must rely on external sources, usually men, to make sense of their lives." Female stereotypes continue to thrive in the media we consume every day. Parry and Karam (2001:383) are of the opinion that the media have always possessed the 
power to impart ideological as well as patriarchal messages and these pervasive media messages have a strong influence on females' role in society and their development of identity. The subjective representations of women are often framed by media producers who are influenced by the political economy of the media.

Stereotypical perceptions of women are endowed in our society. Berger (1972:10) affirms this and maintains that the issues of masculinity and femininity are constructed by our societies. Directly or indirectly, media send the message that character, integrity and social contribution are less important than outward physical appearance. The presence of media is often taken for granted as its impact can be subtle as well as compelling. Media can have a strong effect on how women view and interpret the world around them. Women are looking to understand the world, recognise their sense of self and find their place in society and they use the media as a means to help define, explain their roles and develop their identity. Granello (1997:24-54) is of the view that women seeking information about their current developmental tasks will take that information from any available source.

Media contribute to social change today that is largely overlooked and can be seen as the missing link between culture and personality. Liebau (2007:8) purports that the emphasis on sexiness, revealing fashions, and the overvaluing of physical appeal creates pressure to measure up to bone-slim models or celebrities and leads to unrealistic expectations among women about how their own bodies should actually look. Media has a powerful influence on the socialisation of girls and women and constantly promoting this 'ideal look' greatly restricts the availability of role models for females. Creating and sustaining change must involve challenging media to not only increase the type of coverage of women but to also extend the range of diversity - a true reflection of reality. Geraghty (in Curran and Gurevitch, 1996:265) asks the question "How far can the mass media produce culture which speaks of popular concerns rather than interests of ownership; how do audiences engage with cultural texts as varied as for example, photographs, television series and bestselling novels; and to what extent do the values of popular press or television dominate or control the way in which we think about the world"? Geraghty's questions are highly relevant and based on this, this paper uses magazines as a case study and explores the representation of women in magazines and the extent to which this representation influences gender identity in either empowering or limiting the development of women in society.

\section{Representation and the Media}

Hall (1997:15) describes representation as an essential part of the process by which meaning is produced and exchanged between members of a culture. It involves the use of language, of signs and images which stand for or represent things. According to Hall (1997:15) representation is the use of language and signs to say something meaningful about, or to represent the world meaningfully to other people. Hall (1997:16) adds that representation is the construction of meaning through language. Language, signs and images plays an important role in shaping and developing what people perceive as reality and thereby developing their identity. Talbot, Atkinson and Atkinson (2003:4) state that a common perspective is that language and signs play a vital role in constituting people's reality and this insight has evident implications for the power and influence of media language.

The way in which media representations resource and guide consciousness and understanding, and exert influence through interpretation varies according to general forms and purposes. The media are particularly important in contemporary society for a variety of reasons and Talbot, Atkinson and Atkinson (2003:5) affirm that "for many people media has become increasingly accessible and often dominant in daily life, partly or wholly substituting more traditional sources of information such as the Church, trade unions and so on. They make powerful contributions to our understanding of what is public and what is private in contemporary life and they tend to naturalise these distinctions so that they appear as common sense." This clearly highlights the power of the media and reinforces media's ability to impact and contribute to identity construction.

Further research (Ross, 2010; Fitzpatrick, 2009; Liu, 2006; and Fields, 2005) also support this view. The media therefore, are powerful agents of socialisation, a carrier of culture, and a way of communicating ideology (O'Shaughnessy \& Stadler, 2006:327). The media are therefore seen as important vehicles in giving constructions, images and representation of discourses around issues of gender identity by stereotyping the identity of women. Hall (1997:15) describes representation as an essential part of the process by which meaning is produced and exchanged between members of a culture. It involves the use of language, of signs and images which stand for or represent things. Hall's (1997) work has explored representation as a signifying practice in a rich diversity of social contexts and examines the way that media keep those who are powerful in society in control, while at the same time, keeping the powerless people powerless.

The media also has the power to influence society by conveying stereotypical and patriarchal representations of women. Rudy, Popova and Linz (2011:151-159) believe that when women are portrayed in the media, they are often 
sexualized, typically by showing them in scanty or provocative clothing. If the media focus their attention and continuously play down the achievements and contribution of women in society these patterns will become internalised and accepted as the norm. The media can and therefore should play an important role in empowering women by raising the public profile of women's role in society. McQuail in Pinto and Sousa (2011:129) state that we have also entered a period in which the mass media are becoming more central and more important to the political, economic and cultural life of societies and in some respects, they can be thought of as actually more powerful. To this end, the following theories become relevant and are explained:

\subsection{The Media Effect Theory}

The Media Effect Theory specifically examines the impact of the media on society and focuses on the effect of the media on personal behaviour and it's the effects of the media on society and culture in general (Fourie, 2007:103). This outlines the simplified assumptions about the power of the media and then gradually develops complex and multiple assumptions, saying a lot not only about the media, but about the effect that the media has on society and humanity as such. Fourie (2007:237) believes that the underlying assumption of long term theories is that media do not have an immediate impact on behaviour and people's way of thinking, but can affect behaviour over a longer period of exposure to media content.

\subsection{The Agenda Setting Theory}

The Agenda Setting Theory relates to the dynamics of issues and how they are ranked or accorded legitimacy and priority. According to O'Shaughnessy and Stadler (2005:24) agenda setting is the process by which media producers and setup the issues - the agenda - that the media will focus on and that audiences will subsequently perceive those issues to be important. Agenda setting refers to instances in which media coverage draws attention to an issue or events and 'puts it on the agenda' for public discussion and debate. The theory states that the mass media, simply by the fact of paying attention to some issues and neglecting others, will have an effect on public opinion. In relation to this study, if the media focuses the majority of their attention on portraying women as sex objects, this could impact and contribute significantly to women's development of self-identity, self-image and self-esteem. The media therefore consciously or unconsciously creates a particular image of reality. This means that the omission of certain events and issues, and the overemphasis of others, establish a particular way for media users to think about reality and therefore sets an agenda of inclusion or exclusion. The long term effects of inclusion and exclusionary practices of the media would therefore influence society in a certain way.

\subsection{The Social Expectation Theory}

The Social Expectation Theory outlines the long-range and indirect influences of the media. This theory pertains to socialisation influences of mass communications that result from their portrayals of stable patterns of group life. This theory shows that people can use the mass media as sources, either deliberately or without conscious awareness, from which to acquire guidelines for appropriate behaviour that will help them adapt to the complex world in which they live. Fourie (2007:186) maintains as powerful socialisation instruments, media contribute towards integration, harmony and cohesion through information, education and entertainment. The theory helps in explaining how certain kinds of media representations and content can play a part in the long-term socialisation of people in a society where mass communications are available.

\subsection{The Feminist Media Theory}

In the case of gender representation the Feminist Media Theory focuses on gender issues, specifically the representation of women and its consequent impact. Van Zoonen (1994:11) states that the media have always been at the centre of feminist critique. Furthermore, the media have been thought to act as socialisation agents. Media are perceived as the main instruments in conveying, respectively, stereotypical, patriarchal and hegemonic values about women and femininity. Borzekowski, Robinson and Killen (2000:36-41) maintain that when women do get into media space a substantial proportion of it is actually derogatory or focused excessively on physical appearance. Feminist theories and their critical application offer a variety of ways to expand our knowledge on gender issues. Feminist theories offer a base from which to question and enlarge our epistemologies, ideals, values and our culture and therefore lend a gendered inflection of the representation of women in the media and the influence on identity construction. 
The aforementioned clearly indicates that words and stereotyping by the media impacts on identity. Based on this, this study explores the representation of women in magazines and the extent of how this representation influences gender identity.

\section{Research Methodology}

This study employed a qualitative research methodology. A case study method was used to explore the representation of women in magazines and the extent to which this representation influences gender identity in either empowering or limiting the development of women in society. Yin (2009:187) states that in qualitative research, a case study is an intensive investigation of a single unit and uses multiple variables. The study involved an examination of content in selected articles from two of South Africa's leading weekly magazines, namely DRUM and YOU. Categories selected for analysis were the words, sentences (language) and gender stereotypes. The primary unit of analysis was texts from DRUM and YOU magazine over a 10 week period (10 publications). Content analysis of words and sentences was used to analyse and interpret the way women were represented from text collected. Jacob (2006) explains that to conduct a content analysis on any text, the text is coded or broken down into manageable categories on a variety of levels: word, word sentence, phrase, theme, visuals and then examined using one of content analysis's basic method, conceptual analysis or relational analysis. Relational analysis was used as the focus extends beyond the frequency of specific words, phrases and themes, to the emergent meanings. This paper therefore uses the above categories to examine magazines representation of women and the impact on identity construction.

\section{Findings and Analysis}

\subsection{Words and Sentence usage (Language)}

Language has an instrumental role in shaping people's perception of reality. By the use of language, media often focuses on the conventional, feminine roles of females such as wife, sister and mother. This is evident in an article about the National Freedom Party's (NFP) leader, Zanele Magwaza-Msibi. The article focuses on Magwaza-Msibi being a strong Zulu woman and political leader and states "At home I submit to my husband" (DRUM, Page14, 10 April 2014). This statement is emphasised as it appears on the cover of the magazine. YOU and DRUM publication covers further highlight media's focus on women's stereotypical roles, "Meeting my husband online and my steamy fling with Ronn Moss"; "Legendary Candy Moloi and daughter Lerato talk about family and marriage"; "Isibaya's Thembe Nyandeni on losing her son and being older." These media headlines encourage readers to define women in the context of the family as wives and mothers. Milestone and Myers (2012) affirm that media feed into the 'conventional ideology of femininity and 'frames marriage and family as life-goals.'

Liebau (2007:8) purports that the emphasis on sexiness, revealing fashions, and the overvaluing of physical appeal creates pressure to measure up to bone-slim models or celebrities and leads to unrealistic expectations among women about how their own bodies should actually look. An article headlined "Boity's Cheeky move....she's the talk of the town since baring her pert posterior in a glossy mag" (YOU, Page 22, 6 March 2014) features Boity Thulo's frenzy about pictures of her bottom. The article is accompanied by a picture of Boity's naked shoot and the cover of the magazine is headlined 'Bootylicious Boity'. The words 'cheeky' and 'bootylicious' are riddled with sexual innuendo. The article also describes her as the 'petite actress.' This coverage sends the message that in order for women to be successful and noticed, she must be skinny. The article further defines women in terms of the way men perceive them - as sex objects. Media has a powerful influence on the socialisation of girls and women and constantly promoting this 'ideal look' greatly restricts the availability of role models for females.

Women are often besmirched and devalued in the media and this is evident in an article titled "Fergie's roller coaster" (YOU Magazine, Page 102, 13 March 2014). Excerpts from the article stated "the mom of two, who at one point tipped the scales at $101 \mathrm{~kg}$ and was dubbed the Duchess of 'Pork'....has followed a rigorous three-month exercise programme in the Swiss Alps. The Duchess of York appears to be winning the battle of the bulge - but her yo-yo dieting has taken its toll on her looks...one moment she is lean and luscious the next she is puffy and a bit thick in the waist". This article severely annihilates the Duchess of York as majority of the article focuses on her physical appearance. In addition, the word 'Pork' equates the Duchess of York to a pig.

Women's remarkable accomplishments often go unnoticed and excerpts from an article about former Miss SA's Thuli Sitole who is a single mom authenticates this. The opening line of the article stated "Sections of her long dark hair are pinned up as a stylist creates a few curls" (YOU, Page 110, 27 February 2014). This article indicates that reporters 
often use descriptive words that emphasise 'femininity,' physical appearance and underplay women's accomplishments. The entire two page article focuses on her pregnancies, her marriage, break-up and role as mother and the only mention of her successful career is at the end of the article despite the fact that the article's headline states that she wants to retire at 35 - would could only mean that she is very successful career woman.

Women are looking to understand the world, recognise their sense of self and find their place in society and they use the media as a means to help define, explain their roles and develop their identity. The exclusion of certain issues in the media and the overemphasis of others can establish a particular way for media users to think about reality.

\subsection{Gender Stereotypes}

Stereotypical perceptions of women are endowed in our society. Berger (1972:10) affirms this and maintains that the issues of masculinity and femininity are constructed by our societies. Directly or indirectly, media send the message that character, integrity and social contribution are less important than outward physical appearance. Content in articles and advertisements constantly allude that women's bodies are 'in need of fixing' with headlines ranging from "How to look subtly sexy, Hot new ways to get slim; Two in one diets, Slimming secrets; Body fat reduction techniques, engulfing magazine content. Furthermore, women are constantly glamorised and used to sell products. This false world created makes it difficult for readers to differentiate between the real world and that which is illusionary.

The presence of media is often taken for granted as its impact can be subtle as well as compelling. Media can have a strong effect on how women view and interpret the world around them. Granello (1997:24-54) is of the view that women seeking information about their current developmental tasks will take that information from any available source. Media contribute to social change today that is largely overlooked and can be seen as the missing link between culture and personality.

According to Soobben and Rawjee (2013) the media stereotypes woman to be raised as consumers of the future domestic, caring and objects of beauty rather than producers. Both magazines cover stories predominantly on celebrities, relationships, sexuality and beauty and thrive on the role that romance, love and drama play in a woman's life. This can be seen in headlines "I'll date whoever I like - Sophie', Dirty secrets of squeaky clean Gwyneth,' 'Flirting 101 for shy peeps' and Meeting my husband online and my steamy fling with Ronn Moss', all of which appeared on the front pages on YOU and DRUM magazine.

Furthermore, media often portray women as unblemished, coy and figure conscious and coverage of women as frail and emotional beings has not been extricated. This is evident in an article where the opening line states "As the crown was placed on her pretty brunette head the crowd went wild...But for someone who'd just won the country's most coveted beauty title, Rolene Strauss seemed remarkably composed - no tears or melodrama from her" (DRUM, Page 24; 10 April 2014). The writer highlights the stereotypical view that women are assumed to be 'the weaker sex' more emotional and dramatic. This type of reporting objectifies women and undermines their prowess.

\section{Conclusions and Recommendations}

The major findings indicate that stereotypical, dismissive and confining representations of women prevail in media content. Creating and sustaining change must involve challenging media to not only increase the type of coverage of women but to extend the range of diversity to include coverage of the remarkable achievements of women including larger women, women with disabilities, older women, racial and ethnic minorities - a true reflection of reality. Media often objectifies women by constantly portraying them as glamorous sex objects. When they do appear in media content, their achievements are downplayed and trivialised. This subjective reporting of women is a tragic undervaluing of the extraordinary accomplishments of women.

The magazine industry is driven by profit-making and this frames the way it represents gender and it is clear that media benefit from portraying women in particular ways. Both magazines suggest that women always need to improve their physical appearance. Cellulite and stretch marks are described as repulsive and women are persuaded to consume products to get rid of these 'flaws'. Media professionals need to celebrate the accomplishments of women and those that fail to do so, fail in their professional responsibility. As an influential institution, the media cannot consistently reinforce and reproduce stereotypical discourses about gender - it has a concomitant responsibility to be a vehicle of transformation in South Africa. Based on the findings, the following recommendations are offered:

- Media professionals need to contribute to South Africa's transformation ideals by not misrepresenting women

- Journalists should guard against using language that implies weakness and should focus on the extraordinary achievements of women 
- The representation of women as role models with diverse roles and new identities that deviates from the patriarchal representations needs more exposure.

\section{References}

Berger, J. (1972). Ways of Seeing. London: British Broadcasting Corporation and Penguin Books.

Borzekowski, D. L., Robinson, T. N., and Killen, J. D. (2000). Does the camera add 10 pounds? Media use, perceived importance of appearance, and weight concerns among teenage girls. Journal of Adolescent Health, 26(1), $36-41$.

Curran, J, and Gurevitch, M. (Eds.). (1996). Mass Media and Society. London: Arnold.

Fields, B. (2005). School Discipline Coverage in Australian Newspapers: Impact on Public Perceptions, Educational Decisions and Policy. In: AARE 2005: Australian Association for Research in Education Annual Conference 2005: Creative Dissent: Constructive Solutions. Australia, 27 Nov - 1 Dec 2005. Parramatta: University of Southern Queensland, 2-15.

Fitzpatrick, S. (2009). Covering Muslim Women at the Beach: Media Representations of the Burkini. UCLA Center for the Study of Women Thinking Gender Papers [online]. Available at: http://repositories.cdlib.org/csw/thinkinggender/TG09_Fitzpatrick. [Accessed 16 October 2013].

Fourie, P.J. (2007). Media Studies: Media History, Media and Society. Vol. 1. $2^{\text {nd }}$ ed. Landsdown: Juta.

Granello, D. H. (1997). Using Beverly Hills, 90210 to explore developmental issues in female adolescents. Youth and Society, 29 (1), 2454.

Hall, S. (1997). Representation - Cultural Representations and Signifying Practices. London: Sage Publications Ltd.

Jacob, B. (2006). Content Analysis. http://en.articlesgratuits.com/content-analysis-as-a-research-tool-id998.php [Accessed 15 February 2014]

Liebau, C. P. (2007). Prude: How the sex obsessed culture damaged girls. Boston, MA: Centre Street Publishing.

Liu, S. (2006). An examination of the effects of print media exposure and contact on subjective social reality and acculturation attitudes. International Journal of Intercultural Relations, 30, 365-382.

Milestone, K. \& Meyer, A. (2012). Gender and Popular Culture. Cambridge:Polity Press.

Naigle, D. (2005). Literature Review of Media Messages to Adolescent Females. Educational

Communications and Technology University of Saskatchewan. Available at: http://www.usask.ca/education/coursework/802papers/ naigle/index.htm, [Accessed 19 July 2013].

O'Shaughnessy, M. and Stadler, J. (2005). Media and Society - An Introduction. 3rd ed. Sydney: Oxford University Press.

Parry, L. and Karam, B. (2001). Feminist Media Theory. In: Fourie P.J. Media Studies: Institutions, Theories and Issues. Vol.1. Landsdowne: Juta Education.

Peirce, K. L. (1990). A feminist theoretical perspective on the socialization of teenage girls through Seventeen magazine. Sex Roles, 23, 491-500.

Pinto, M. and Sousa H. (2011). Communication and Citizenship: Rethinking crisis and change. In IAMCR Braga Conference Communication and Society Research Centre. Portugal, 18 - 22 July, 2010. Minho: Portugal, 15-149.

Ross, K. (2010). Gendered media: Women, men and identity politics. Lanham: Rowman and Littlefield Publishers Inc.

Rudy, R.M; Popova L and Linz, D.G. (2011). Contributions to the Content Analysis of Gender Roles: An introduction to a special issue, 64 (3), 151-159.

Sanders, E.L. (2009). The Influence of media Marketing on Adolescent Girls. Available at: http://www.kon.org/urc/v8/sanders. html. [Accessed 20 November 2013].

Soobben, D \& Rawjee, V.P. (2013). Ethnic Media and Identity Construction: The Representation of Women in an Ethnic Newspaper in South Africa. In: International Conference on Human and Social Sciences. Vol. 2. Rome-Italy, September 20-22, 2013.

Talbot, M., Atkinson, K. and Atkinson, D. (2003). Language and Power in the Modern World. Edinburgh: Edinburgh University Press Ltd. Van Zoonen, L. (1994). Feminist Media Studies. London: Sage Publications.

Yin, R.K. (2009). Case Study Research: Design and Methods. $4^{\text {th }}$ ed. Thousand Oaks: Sage. 